\title{
Olhares de professores homens de Educação Infantil: conquistas e preconceitos
}

\author{
Josiane Peres Gonçalves* \\ Adriana Horta de Faria ${ }^{* *}$ \\ Maria das Graças Fernandes de Amorim dos Reis ${ }^{\text {**** }}$
}

\section{Resumo}

O objetivo desta pesquisa é verificar quais são as representações sociais de professores homens que atuam com crianças na faixa etária de 0 a 5 anos matriculadas em instituições públicas de educação infantil no Estado de Mato Grosso do Sul. Como metodologia foi usada a técnica de entrevista a partir de questionário semiestruturado, entrevistas que foram gravadas em áudio, transcritas e analisadas sob a perspectiva das representações sociais com professores de quatro municípios do referido Estado. Os resultados apontam que os professores do sexo masculino são limitados quanto à sua atividade, pois não é permitido que executem tarefas próprias da profissão, como banho e troca de fraldas, pois o receio da pedofilia é evidente. As discussões sugerem que poucos homens optam pela carreira docente, isso devido ao fato de ser considerada uma profissão feminina. Como conclusão, pode-se afirmar que a educação infantil deve oferecer às crianças contato com adultos, que são as suas referências, de ambos os sexos, especialmente na escola, local em que elas iniciam a socialização fora da família. Nesse sentido, pode-se afirmar que homens podem, sim, contribuir de forma positiva com o processo de educação escolar de crianças.

Palavras-chave: Representações Sociais. Educação Infantil. Homens Professores.

\footnotetext{
* Doutora em Educação pela Pontifícia Universidade Católica do Rio Grande do Sul (PUC/RS). Professora dos Cursos de Ciências Sociais e Pedagogia, do Campus de Naviraí, e do Programa de Pós-Graduação em Educação, campus Pantanal, pela Universidade Federal do Mato Grosso do Sul (UFMS).

** Graduada em Pedagogia pela Universidade do Mato Grosso do Sul (UFMS). Mestranda em Educação pela Universidade Federal da Grande Dourados (UFGD).

*** Doutora em Educação pela Universidade Federal de São Carlos (UFSCar). Professora do Curso de Pedagogia na Universidade Federal do Mato Grosso do Sul (UFMS).
} 


\section{Introdução}

O presente trabalho vincula-se à pesquisa intitulada "Representações Sociais de Famílias, Gestores e Docentes do Gênero Masculino do Estado de Mato Grosso do Sul sobre a Atuação de Homens Professores com Crianças". Esse viés da pesquisa buscou identificar as representações sociais e as questões de gênero entre os homens que trabalham como professores de crianças de 0 a 5 anos de idade, matriculadas em instituições públicas de educação infantil.

A educação infantil é marcada pela predominância de mulheres atuando com as crianças e a presença de homens nesse ambiente é escassa. Assim, a pesquisa se justifica como relevante por investigar a percepção do próprio professor, visto que está diretamente ligado à ação, sendo então sujeito da realidade em que vive, podendo relatar o que percebe das famílias, dos gestores e também das próprias crianças diante da sua presença.

Partindo desse princípio, busca-se esclarecer alguns questionamentos relativos às representações desse professor homem sobre sua atuação: estando em um ambiente de predominância feminina, percebe ele resistência por parte da comunidade escolar? Qual a reação dos pais ou responsáveis pelas crianças da educação infantil ao perceberem a presença de professor do gênero masculino? Visto que a grande particularidade da educação infantil é o cuidar e o educar, como o professor lida com as tarefas próprias da profissão? Que motivos o levaram a trabalhar na educação infantil? E, de acordo com as suas representações, por que poucos homens optam pela carreira docente na educação infantil?

A pesquisa foi realizada em duas etapas, a primeira por meio de telefonemas para as secretarias ou gerências de educação de todos os municípios do estado de Mato Grosso do Sul, para localizar professores homens atuando na educação infantil. Após a escolha das cidades a serem visitadas e dos sujeitos, foi iniciada a pesquisa de campo, realizando entrevistas a partir de questionário semiestruturado, gravadas em áudio, transcritas e analisadas, buscando alcançar o objetivo desta pesquisa de analisar as representações sociais e as questões de gênero colocadas pelos docentes.

\section{As relações de gênero}

As relações de gênero são resultado de um processo pedagógico que se inicia no nascimento e segue ao longo de toda a vida. Na nossa sociedade, esse processo vem reforçando a desigualdade existente entre homens e mulheres, principalmente em torno da sexualidade, da reprodução, da divisão sexual do trabalho e do âmbito público/cidadania. 
No que se refere ao gênero humano, desde sempre as sociedades vêm indicando distintos papéis sociais para homens e para mulheres, assim impondo a função de cada indivíduo na sociedade. Essas relações acabam por fazer com que se idealize o que é habitual a um homem praticar ou até mesmo o que não é natural de a mulher realizar. Entretanto, a desigualdade entre homem e mulher é construída socialmente e não se dá por força da diferença biológica de cada um, ou seja, é algo construído social e culturalmente. Dessa forma, a literatura educacional sugere que gênero é uma representação social relacionada ao autoconceito de ser homem ou de ser mulher:

Gênero é a organização social da diferença sexual. Ele não reflete a realidade biológica primeira, mas ele constrói o sentido desta realidade. A diferença sexual não é a causa originária da qual a organização social poderia derivar; ela é, antes, uma estrutura social móvel que deve ser analisada nos seus diferentes contextos históricos. (SCOTT, 1998, p. 15).

Nessa perspectiva, compreende-se por sexo a diferença biológica existente entre homem e mulher, enquanto gênero, por outro lado, é uma construção social e histórica que fundamenta a distinção e a relação entre o feminino e o masculino. Gonçalves (2009, p. 26) relata que "[...] o sexo se refere às diferenças biológicas de homens e mulheres, enquanto que gênero é um construto social relacionado à forma como historicamente os grupos sociais foram criando e efetivando os padrões de comportamentos para ambos os sexos".

Nas relações de gênero na educação escolar brasileira, inicialmente, somente homens atuavam como professores, contudo a educação de crianças pequenas fora do ambiente doméstico foi, no início, de caráter assistencialista, e as mulheres se ocupavam de cuidar dos filhos das mães que trabalhavam. As mulheres foram consideradas como as mais indicadas para essa tarefa, pois a habilidade de cuidar de crianças era entendida como característica inata neste gênero. Para Louro (2012), a inserção das mulheres como professoras no mercado de trabalho passou a ser vista como uma extensão da maternidade:

Afirmavam que as mulheres tinham, "por natureza", uma inclinação para o trato com as crianças, que elas são as primeiras e "naturais educadoras". Portanto, nada mais adequado do que lhes confiar a educação dos pequenos. Se o destino primordial da mulher era a maternidade, bastaria pensar que o magistério representava, de certa forma, uma "extensão da maternidade", cada aluno ou aluna vistos como filho ou filha “espiritual”. (LOURO, 2012, p. 450).

Nessa perspectiva, para exercer o papel docente, consideravam que a mulher estava preparada, pois já possuía o dom de cuidar, tarefa que ela já executava em seu lar. Pode-se atribuir isso ao fato de 
que as primeiras instituições que atendiam as crianças surgiram com um caráter assistencialista, com o intuito de auxiliar as mulheres que trabalhavam fora de casa e as viúvas desamparadas. Ressalta-se que essas organizações não tinham caráter pedagógico.

Outro aspecto que auxiliou no surgimento dessas instituições foi que não se tinha um conceito bem definido sobre as especificidades da criança, pois, historicamente, era "[...] concebida como um objeto descartável, sem valor intrínseco de ser humano" (RIZZO, 2003, p. 37). As situações de alto índice de mortalidade infantil, a desnutrição generalizada e o número significativo de acidentes domésticos fizeram com que alguns setores da sociedade, dentre eles o religioso, o empresarial e o educacional, começassem a pensar num espaço de cuidados para as crianças fora do âmbito familiar. A partir dessas condições, a criança passa a ser vista pela sociedade com um sentimento filantrópico, beneficente. Então passa a ser atendida fora da família sob os parâmetros do assistencialismo (DIDONET, 2001). Assim, o autor enfatiza:

Enquanto para as famílias mais abastadas pagavam uma babá, as pobres se viam na
contingência de deixar os filhos sozinhos ou colocá-los numa instituição que deles
cuidasse. Para os filhos das mulheres trabalhadoras, a creche tinha que ser de tempo
integral; para os filhos de operárias de baixa renda, tinha que ser gratuita ou cobrar
muito pouco; ou para cuidar da criança enquanto a mãe estava trabalhando fora de
casa, tinha que zelar pela saúde, ensinar hábitos de higiene e alimentar a criança. A
educação permanecia assunto de família. Essa origem determinou a associação creche,
criança pobre e o caráter assistencial da creche. (DIDONET, 2001, p. 13).

Ao longo da história, enquanto as instituições públicas atendiam as crianças das camadas mais populares, as propostas das particulares, de cunho pedagógico, funcionavam em meio turno, dando ênfase à socialização e à preparação para o ensino regular. As crianças das diferentes classes sociais eram submetidas a contextos de desenvolvimento desiguais, já que, enquanto as crianças das classes menos favorecidas eram atendidas com propostas de trabalho que partiam de uma ideia de carência e deficiência, as crianças das classes sociais mais abastadas recebiam uma educação que salvaguardava a criatividade e a sociabilidade infantil (KRAMER, 1995).

Com a preocupação de atender todas as crianças, independentemente da sua classe social, iniciou-se um processo de regulamentação desse trabalho no âmbito da legislação, originando documentos específicos para a educação de crianças pequenas. Primeiramente ocorreu uma regulamentação na Constituição Federal de 1988 (BRASIL, 1988), que, após uma longa batalha, que envolveu diferentes setores da sociedade, como o movimento de mulheres, de trabalhadores e de educadores, reconheceu a educação infantil como direito social das crianças e dever do Estado. 
A Lei de Diretrizes e Bases da Educação Nacional (Lei Federal nº 9.394/1996), conhecida pela sigla LDB, em seu artigo 29 destaca que o objetivo principal da educação infantil é o desenvolvimento integral da criança: "A educação infantil, primeira etapa da educação básica, tem como finalidade o desenvolvimento integral da criança de até 5 (cinco) anos, em seus aspectos físico, psicológico, intelectual e social, complementando a ação da família e da comunidade” (BRASIL, 1996).

As Diretrizes Curriculares Nacionais para a Educação Infantil (DCNEI), documento de caráter mandatório, apresentam a concepção de educação infantil vigente e estabelecem os princípios éticos, políticos e estéticos que devem guiar as propostas pedagógicas desse ciclo. Essas propostas devem ter como objetivo "[...] garantir à criança acesso a processos de apropriação, renovação e articulação de conhecimentos e aprendizagens de diferentes linguagens, assim como o direito à proteção, à saúde, à liberdade, à confiança, ao respeito, à dignidade, à brincadeira, à convivência e à interação com outras crianças" (BRASIL, 2010, p. 13).

Outro documento elaborado com a intenção de contribuir para a implementação de práticas educativas de qualidade no interior dos Centros de Educação Infantil é o Referencial Curricular Nacional para a Educação Infantil (BRASIL, 1998). Esse documento foi concebido de maneira a servir como um guia de reflexão de cunho educacional sobre os objetivos, conteúdos e orientações didáticas para os profissionais que atuam com crianças de 0 a 6 anos de idade. Dessa forma, a Educação Infantil ganha aspecto educativo e reconhece a criança como cidadão, buscando o seu crescimento integral, vale dizer, crescimento em seus aspectos físico, motor, psicológico, cognitivo e social, complementando a ação da família e da comunidade.

A especificidade da educação infantil está no binômio educar/cuidar e o cuidado e a educação de crianças têm sido habitualmente, em nossa cultura, imputados à atuação das mulheres. (SAYÃO, 2005). Em decorrência disso, pode-se afirmar que a maioria dos docentes nessa faixa de ensino são mulheres. Um dos principais argumentos que se usa em favor da permanência das mulheres professoras é o seu presumido instinto maternal, considerado como inato e mais adequado ao seu papel de educadora.

Arce (2001), em seus estudos, afirma que existe um mito em relação a esse papel congênito de educadora atribuído às mulheres, sobre o qual apresenta as seguintes conclusões:

Trabalhando com esta acepção de mito, constatei, mediante estudos, que a constituição histórica da imagem do profissional da educação infantil tem estado fortemente impregnada do mito da maternidade, da mulher como a rainha do lar, educadora nata, cujo papel educativo associa-se necessariamente ao ambiente doméstico, sendo assim, 
particularmente importante nos primeiros anos da infância. O início da educação de todo indivíduo deveria, assim, ser uma extensão natural da maternidade. Cumpre, entretanto, destacar que este mito da mulher mãe e educadora nata exerce seu maior poder orientador no período relativo aos anos iniciais da vida do indivíduo, não sendo atribuído à mulher a responsabilidade sobre a educação em geral. (ARCE, 2001, p. 4).

Assim, a concepção de que a mulher é a melhor educadora para crianças pequenas foi assimilada e adotada pela sociedade. Trata-se de representações sociais que contribuíram para o afastamento dos homens do magistério e para o aumento da participação feminina no ambiente escolar.

\section{Representações sociais}

O conceito das "representações sociais" pode ser visto como uma interpelação sociológica da Psicologia Social. Segundo Moscovici (1973), o precursor da teoria, o objetivo das representações sociais é tornar familiar algo não familiar, ou seja, naturalizar processos que não são naturais, e sim construídos socialmente.

O autor define as representações sociais da seguinte forma:

[...] um sistema de valores, ideias e práticas com uma dupla função: primeiramente, estabelecer uma ordem que habilitará os indivíduos a orientarem-se em seu mundo material e social e dominarem-no; e, em segundo lugar, possibilitar a realização da comunicação entre os membros de uma comunidade pelo fornecimento de um código para o "intercâmbio" social e de um código para nomearem e classificarem, sem ambiguidades, os diversos aspectos de seu mundo e de sua história individual e em grupo. (MOSCOVICI, 1973, p. 17).[

Logo, é de se entender que as representações sociais são um complexo de conceitos e de explicações da vida cotidiana, são uma forma complexa de elaboração dos saberes sociais. O propósito da chamada teoria das representações sociais é esclarecer as concepções coletivas do homem a partir de uma perspectiva coletiva, sem perder de vista a individualidade.

Assim, as representações sociais têm como pilar um pensamento já preexistente, um pensamento que se constitui com um sistema de crenças, de valores e de imagens e então assume uma posição de vínculo entre o indivíduo e a sociedade, mantendo a continuidade das ideias que prevalecem na coletividade. Dessa forma, o sujeito, para ser aceito em seu grupo social, segue os preceitos previamente estabelecidos. Moscovici (2004, p. 210) pondera que: 
[...] as representações sociais se apresentam como uma "rede" de ideias, metáforas e imagens, mais ou menos interligadas livremente [...] parece que não conseguimos nos desfazer da impressão de que temos uma "enciclopédia" de tais ideias, metáforas e imagens entre si de acordo com a necessidade dos núcleos, das crenças centrais armazenadas separadamente em nossa memória coletiva e ao redor das quais essas redes se formam. (MOSCOVICI, 2004, p. 210).

As representações sociais constituem os modos pelos quais os grupos sociais constroem e organizam diferentes significados dos estímulos do meio social e as possibilidades de respostas que podem acompanhar esses estímulos, ou seja, a forma de pensamento da sociedade interfere em suas ações e estas, por sua vez, afetam a sociedade. Alves-Mazzotti (2009), em suas análises a respeito da teoria das representações sociais, sustenta que:

Já no caso das representações sociais, parte-se da premissa de que não existe separação entre o universo externo e o universo interno do sujeito: em sua atividade representativa, ele não reproduz passivamente um objeto dado, mas, de certa forma, o reconstrói e, ao fazê-lo, se constitui como sujeito, pois, ao apreendê-lo de uma dada maneira, ele próprio se situa no universo social e material. Além disso, afirma que as representações sociais, tal como as opiniões e as atitudes, são "uma preparação para a ação", mas, ao contrário dessas, não o são apenas porque orientam o comportamento do sujeito, mas principalmente porque reconstituem os elementos do ambiente no qual o comportamento terá lugar, integrando-o a uma rede de relações às quais está vinculado o seu objeto (ALVES-MAZZOTTI, 2009, p. 22-23).

Na educação, a concepção de que a mulher é a melhor educadora para crianças pequenas foi absorvida pela sociedade. Trata-se de representações sociais que contribuíram para o afastamento dos homens do magistério e para aumento da participação feminina no ambiente escolar. Considerando esse panorama, buscou-se, com este estudo, analisar as representações sociais dos professores do sexo masculino e as questões de gênero colocadas por esses indivíduos, tendo em vista as especificidades que rodeiam o fato de haver poucos homens atuando na educação infantil.

\section{Metodologia}

Este estudo consiste em uma pesquisa qualitativa, ou seja, trata-se de um tipo de pesquisa que, de acordo com Minayo (1998), é capaz de incorporar as questões de significado e de intencionalidade como inseparáveis dos atos, das relações e das estruturas sociais. 
Foram feitas questões de ordem prática para verificar a trajetória profissional dos professores e a sua rotina e questões subjetivas a fim de constatar as representações dos pais em relação à rotina e as práticas pedagógicas. Esse trabalho buscou verificar e analisar as representações sociais de homens que atuam como professores da educação infantil em relação ao seu cotidiano profissional e as questões de gênero que permeiam esse ambiente.

O que gerou a principal questão foi o fato de os profissionais que atuam com essas crianças serem majoritariamente mulheres, contudo, segundo o que afirma Ramos (2011), a presença masculina no ambiente escolar é vista como necessária e positiva ao desenvolvimento emocional da criança. Assim, mesmo escassa, porém existente, a presença de homens atuando com crianças na educação infantil é abordada nesta pesquisa a partir das representações sociais relativas a esses raros profissionais. Segundo Alves-Mazzotti (2009), esse modelo de pesquisa permite verificar em que se baseiam as ações executadas na educação. A autora versa:

O estudo das representações sociais parece ser um caminho promissor para atingir esses propósitos na medida em que investiga justamente como se formam e como funcionam os sistemas de referência que utilizamos para classificar pessoas e grupos e para interpretar os acontecimentos da realidade cotidiana. Por suas relações com a linguagem, a ideologia e o imaginário social e, principalmente, por seu papel na orientação de condutas e das práticas sociais, as representações sociais constituem elementos essenciais à análise dos mecanismos que interferem na eficácia do processo educativo. (ALVES-MAZZOTTI, 2009, p. 21).

Para coleta de dados foi selecionado o instrumento "entrevista", realizado a partir de um questionário semiestruturado. O propósito dessa escolha foi, principalmente, o de captar a espontaneidade das falas dos entrevistados. Esse é um dos métodos que, segundo Spink (1995, p. 100), favorece a expressão de representações sociais:

As técnicas verbais são, sem sombra de dúvida, a forma mais comum de acessar as representações. [...] Dar voz ao entrevistado, evitando assim impor as preconcepções e categorias do pesquisador, permite eliciar um rico material, especialmente quando este é referido às práticas sociais relevantes ao objeto da investigação e às condições de produção das representações em pauta. (SPINK, 1995, p. 100, grifo do autor).

Com esteio nessas ideias foram elaboradas questões semiestruturadas para que os professores expusessem com liberdade as suas representações e as questões de gênero relacionados à rotina, à escolha da profissão, aos motivos que os levaram a trabalhar com a educação infantil, à relação com o cuidado físico da criança, à relação com os demais sujeitos da comunidade escolar, se acreditam ser 
importante aumentar o número de homens atuando nessa etapa da educação e se os homens podem contribuir na educação escolar das crianças.

Para localizar os sujeitos foram feitas ligações para as secretarias de educação de todas as cidades do estado de Mato Grosso do Sul durante o primeiro semestre do ano de 2014. Após localizar os professores do sexo masculino que estavam atuando na educação infantil, foram selecionadas quatro cidades para a coleta de dados: Itaquiraí, por ser uma cidade do extremo sul do estado; Tacuru, por ter um professor indígena; Corumbá, por ser uma cidade pantaneira e que faz fronteira com a Bolívia; e Campo Grande, por ser uma cidade maior e a capital do Estado. Todos os professores entrevistados são regentes, ou seja, passam a maior parte do período com as crianças.

As entrevistas foram gravadas em áudio durante o ano de 2014 e, em seguida, foram transcritas e analisadas. Posteriormente foi feita a leitura/escuta para todos os integrantes do Grupo de Estudo e Pesquisa em Desenvolvimento, Gênero e Educação (GEPDGE). Para Spink (1995, p. 102), “[...] é necessário ficar atento às características do discurso: a variação (versões contraditórias); os detalhes sutis, como silêncios, hesitações, lapsos (investimento afetivo presente); retórica ou organização do discurso de modo a argumentar contra ou a favor de uma versão dos fatos".

Para facilitar a identificação dos sujeitos pesquisados, suas características - como idade, formação, cidade de atuação, etapa da educação infantil em que está atuando, tempo de atuação na educação e tempo de exercício na educação infantil -, foi elaborado o quadro abaixo. Para a preservação da identidade dos entrevistados, os nomes dos participantes da pesquisa encontram-se codificados.

Quadro 1 - Perfil dos Entrevistados

\begin{tabular}{|c|c|c|c|c|c|c|}
\hline Sujeitos & Idade & Formação Acadêmica & $\begin{array}{c}\text { Cidade } \\
\text { MS }\end{array}$ & $\begin{array}{l}\text { Tempo de } \\
\text { Magistério }\end{array}$ & $\begin{array}{l}\text { Atuação na } \\
\text { Educação } \\
\text { Infantil }\end{array}$ & $\begin{array}{c}\text { Turma em que } \\
\text { Atua/idade das } \\
\text { crianças }\end{array}$ \\
\hline PH 1 & 32 & $\begin{array}{l}\text { Normal Superior e } \\
\text { Pós-Graduação em } \\
\text { Administração Escolar. }\end{array}$ & $\begin{array}{l}\text { Campo } \\
\text { Grande }\end{array}$ & 6 anos & 2 anos & $\begin{array}{l}\text { Maternal II } \\
\text { (3 e } 4 \text { anos) }\end{array}$ \\
\hline PH 2 & 33 & $\begin{array}{l}\text { Normal Superior e } \\
\text { Pós-Graduação em: } \\
\text { Psicopedagogia; Mídias na } \\
\text { Educação e Tecnologia em } \\
\text { Educação. }\end{array}$ & Itaquiraí & 14 anos & 1 ano & $\begin{array}{c}\text { Jardim II } \\
(4 \text { e } 5 \text { anos) }\end{array}$ \\
\hline PH 3 & 64 & $\begin{array}{c}\text { Pedagogia } \\
\text { Mestrado em Educação. } \\
\text { (cursado no Paraguai) }\end{array}$ & Corumbá & 31 anos & 16 anos & $\begin{array}{c}\text { Jardim II } \\
\text { (4 e } 5 \text { anos) }\end{array}$ \\
\hline PH 4 & 38 & Magistério e Pedagogia & Tacuru & 16 anos & 16 anos & $\begin{array}{c}\text { Jardim II } \\
\text { (4 e } 5 \text { anos) }\end{array}$ \\
\hline
\end{tabular}

Fonte: Autoras (2015). 


\section{Resultados e discussões}

A primeira questão feita aos professores foi quanto ao que os levou a trabalhar na educação infantil. Verificou-se que todos os entrevistados possuem formação apropriada para o exercício da docência nessa etapa da educação, e buscávamos, com essa indagação, verificar se houve planejamento ou se a opção por atuar com crianças pequenas foi inesperada. $\mathrm{O}$ PH 1 relatou:

Bom, primeiro surgiu o concurso e eu pensei na estabilidade do concurso também, né, e cheguei de paraquedas aqui, quando eu cheguei, eu pensei: "Meu Deus, eu não vou dar conta disso, não!" É totalmente diferente, nunca tinha trabalhado com essa faixa etária, no começo eu tive dificuldade e agora eu gosto da educação infantil, mas no começo eu tive muita dificuldade ${ }^{1}$.

O PH 3 explana seu ingresso na educação infantil da seguinte maneira: “Quando prestei o vestibular, não sabia nem o que significava pedagogia. Quando me mandaram tomar posse em creche, eu fiz concurso meio leigo, sem ter noção do que era aquilo" "2. Isso se enquadra no que Levenfus (1997) caracterizou como uma escolha sem conhecimento da profissão.

Fica evidente que, independentemente da preparação acadêmica, para esses professores a atuação na educação infantil foi inesperada, pois eles não pretendiam inicialmente exercer a profissão docente nessa etapa da educação. De acordo com Santos (2005), a opção por trabalhar como professor da educação infantil é influenciada, num dado momento, pelas condições históricas, sociais e materiais.

O PH 4 fundamenta a sua opção: "Na verdade eu comecei a gostar depois que eu terminei o magistério, assim, porque na verdade para mim tem que gostar de trabalhar na educação infantil, também tem que gostar, assim, das crianças"”.

O que o entrevistado considera por "gostar" pode ser entendido como fragmento da noção de vocação, associada à ideia de talento, este considerado como algo natural, banal e inquestionável. Ocorre, contudo, de acordo com Soares (2002), que a vocação não existe. Não existe nada que seja de nascimento nas características de qualquer profissão em quem a executa. O que encaminha para uma sintonia com determinada profissão são as escolhas que o sujeito faz diante das possibilidades do sistema social e econômico de que participa. Essas escolhas, assim como as escolhas que não faz, é que orientam a sua vida numa determinada direção profissional.

O PH 2 narra a sua motivação para atuar na educação infantil: "Como é a primeira etapa da educação básica tinha um interesse, uma curiosidade"4. O professor relata sobre a sua prática nos primeiros meses: 
Nos seis primeiros meses a gente trabalhava na parte de recreação e então a gente se divertia bastante, brincava, pulava, tudo brincadeira, tudo com um intuito, demonstrava lateralidade, equilíbrio [pausa]. Então foi muito interessante, as crianças, pela pouca idade, elas são muito apegadas. Porque você não para, aqui vale tudo, tem que ensinar de tudo, desde ir ao banheiro a se alimentar, desde o conhecimento da rua do trânsito, da natureza, então não tem uma coisa fixa, então eu acho que a parte da educação infantil que me cativa é essa, eu posso sair de uma borboleta que pousa lá e ir para biologia, tudo de acordo com a faixa etária, eu posso fazer o que eu quiser.

O PH 2 foi o único professor que demonstrou interesse prévio em atuar na educação infantil. É interessante notar que esse sujeito já atuou em vários segmentos da educação, inclusive no cargo de secretário de educação do município de Itaquiraí e, atualmente, leciona também no $5^{\circ}$ ano no contraturno. O PH 2 ainda coloca que as crianças com quem trabalha são "muito apegadas" e comenta: "Por você ser homem elas são mais apegadas ainda, às vezes elas têm primeiro um receio, mas elas se tornam muito apegadas". Quanto a esse "apego", trata-se da afetividade das crianças para com o professor, pois as emoções são para a criança a sua primeira forma de comunicação com o meio, sendo sabido que elas se utilizam das emoções para mobilizar. As relações afetivas influenciam diretamente na aprendizagem e na autoestima da criança, tendo em vista diferenças individuais e comportamentos inerentes ao ser humano (WALLON, 1995).

Diante da colocação do PH 2, relacionada a gênero, de que "por você ser homem" as crianças demonstram mais afeto, foi questionado se ele percebe a mesma reação com as professoras. $\mathrm{O}$ professor responde: “Quando elas veem que é um homem, pela primeira vez, ficam meio ressabiadas. O homem é um pouco diferente, é mais rígido, na brincadeira às vezes a gente não é tão descontraído quanto as mulheres, mas a gente faz, e as pessoas estranham quando veem a gente brincando, pulando pra lá e pra cá".

A estranheza que o PH 2 menciona entre as crianças e que as "pessoas" da comunidade escolar esboçam ao ver um homem atuar como professor de crianças pequenas, segundo a perspectiva das representações sociais, é causada pelo desconhecido, ou seja, pelo não familiar. Sá (1995, p. 37) assim afirma: "[...] o estranho atrai, intriga e perturba as pessoas e as comunidades, provocando nelas o medo da perda dos referenciais habituais, do senso da comunidade e de compreensão mútua”.

A pergunta seguinte está relacionada ao binômio educar/cuidar, característica principal da educação infantil, sendo questionado aos professores como eles lidam com as necessidades específicas do cuidado da criança. Todos os professores versaram sobre o binômio cuidar e educar como uma prática indissociável: O PH 2 declara: "Educar e cuidar, né, eu acho que não tem como cuidar sem 
educar e nem educar sem cuidar, hoje a criança vem, ela aprende uma boa alimentação, ela aprende boas maneiras, ela conhece os meios de transporte, tudo vai ser diferente do que era antes”. De modo semelhante, o PH 1 destaca: “Todo dia você tem que tá falando "não pode fazer isso”, então tem que cuidar e educar ao mesmo tempo, acho que o cuidar e educar estão muito juntos, ao mesmo tempo que você tá educando uma criança, tá o cuidar também. Eles tão brincando, você tá tomando cuidado, cuidado pra não machucar".

Já o PH 3 indica: "Eu acho que é muito importante, a criança aprende brincando, então quando você coloca ela para brincar, você tá cuidando e ao mesmo tempo você tá ensinando".

O professor da educação infantil deve buscar situações significativas de aprendizagem para alcançar o desenvolvimento de habilidades cognitivas, psicomotoras e socioafetivas. Para Craidy e Kaercher (2001, p. 70):

A dicotomia, muitas vezes vivida entre cuidar e o educar, deve começar a ser desmistificada. Todos os momentos podem ser pedagógicos e de cuidados no trabalho com crianças de 0 a 5 anos. Tudo dependerá da forma como se pensam e se procedem as ações. Ao promovê-las proporcionamos cuidados básicos ao mesmo tempo em que atentamos para a construção da autonomia, dos conceitos, das habilidades, do conhecimento físico e social.

Apesar de expressarem conhecimento sobre a importância do binômio educar e cuidar, os professores demonstraram resistência quanto ao cuidado físico para com as crianças, relatando que o cuidado físico, como troca de fraldas e banhos, são executados geralmente por mulheres.

O PH 1 relatou: “Eu vou falar um pouco do preconceito que tem com homem no cuidar, né. No começo tinha aquilo que o homem não podia cuidar, né, eu aqui pelo menos trabalhei 3 anos com o pré e aí eles não usam fralda mais, e o educar faz parte da rotina". Também o PH 3 destaca sobre o cuidado físico necessário a crianças dessa etapa da educação:

Nesse sentido e quando é turma bastante a gente tem que ter uma auxiliar, que é aquela mulher que faz a limpeza das crianças, por que filho dos outros é importante que tenha uma mulher pra fazer a limpeza. Ela dá banho, depois a gente ajuda a vestir, a calçar, a pentear o cabelo, essa coisa toda, mas o banho tem que ser sempre uma mulher, mas aqui logo que começou eu dava banho nas crianças de 3, 4 anos.

Nas representações dos professores, as mulheres é que devem exercer o cuidado físico das crianças. Moscovici (2004) afirma que a representação social é uma "preparação para a ação". O conceito dos professores a respeito do cuidado físico das crianças, que deve ser executado por 
mulheres, é uma representação comum na sociedade, representação que organiza comportamentos e práticas e influencia para a ação e para as relações sociais.

Diante da colocação do professor de que uma mulher é quem cuida da higiene das crianças, foi perguntado a ele se isto acontecia somente naquela instituição ou se era uma prática comum; o PH 3 argumentou:

A atendente tem o papel de limpar as salas, de organizar as coisas e dá banho nas crianças, na falta dela quem faz a limpeza é o professor; eu faço, varro, passo pano e procuro organizar as coisas o melhor possível, sempre a mulher tem mais capricho nas coisas, vamos e convenhamos que é assim, mas a gente também se esforça, mas o banho é sempre elas que fazem.

Foi então o PH 3 questionado se, na falta da atendente, ele dá banho. Ele respondeu: “Não, não. Outra mulher dá banho, mas eu já cheguei a dar banho nas crianças". Frente à colocação de que ele já deu banho nas crianças, perguntamos sobre o porquê da mudança, em que somente mulheres poderiam dar o banho. O professor justifica: "Porque você sabe que a educação, a evolução, as pessoas vão vendo que cada um na sua competência". Questionamos se o banho também era "competência" do professor, e ele se justifica:

Não! Dar banho em criança, não! A gente tem que ajudar a limpar um nariz, mas banho, porque se a gente traz pai, traz a comunidade pra dentro da escola, tem gente de toda formação e sempre tem um que fala: "Ah, eu não quero um homem dando banho no meu filho, não fica bem." Convenhamos nós, não fica bem. Melhor que seja uma moça, uma senhora que vá fazer isso, entendeu?! Não é por problema, mas é que convém que seja assim.

Repete-se a representação dos professores, de que seria mais conveniente que uma mulher tivesse o contato físico necessário com as crianças. Então o cuidado é visto, da maneira que afirma Sayão (2005), como um "fantasma", ou seja, uma coisa que perturba. Especificamente na educação infantil, o cuidado é uma prática indissociável do educar, pois se trata de educar e cuidar. Quando, contudo, se fala de docentes homens, sua atuação é muitas vezes restrita, não lhes sendo permitida ou, por vezes, sendo-lhes fortemente negada, a função de cuidar. O receio da pedofilia fica explicitado quando se trata do toque físico de homens em crianças. A autora sublinha que "[...] continuar negando que há uma dimensão que é corporal na educação dos/as pequeninhos/as significa negar a totalidade do humano e reiterar a velha dicotomia corpo e mente. Esta, sim, constitutiva de uma visão de mundo e de homem/mulher reducionista e binária" (SAYÃO, 2005, p. 154).

Em uma realidade específica, como na comunidade indígena, o PH 4 explica sobre o cuidado físico com as crianças da aldeia: 
Aqui não acontece isso porque criança indígena é assim, muitas vezes eles aprendem a caçar no estilingue, com 4 anos. É com 4 anos [que] eles são mais ativos. São mais ativos, então não tem isso de levar no banheiro, vem próprio de casa, né. Eu imagino assim, as crianças, muitas vezes, a gente não joga responsabilidade porque é criança, né, e a criança indígena é diferente, porque quando ele está com 4 ano ele é muito esperto, né, ele já anda sozinho, né, ele daqui vai lá, a mãe manda "Vai lá na casa do tio e volta", ele não vê como criança que não sabe de nada, como 1 ano, 2 anos, é porque é diferente da cidade. Mas no começo eu sempre trabalho isso com ele porque [com] 3, 4 anos é a primeira vez que ele vai sair da família e entrar em outra família e eles têm sim dificuldade, até uma semana e a gente faz uma brincadeira e mostra onde que é o banheiro masculino, feminino, onde pega o lanche, só que não tem dificuldade.

Na comunidade indígena, os pais são os principais responsáveis pela socialização da criança, contudo os demais membros da aldeia também procuram integrá-las à vida comunitária, transmitindo valores e tradições. A Revista do Conselho Missionário Indigenista (2002) ressalta que a criança indígena adquire os conhecimentos necessários para a vida, aprendendo pelo exemplo e pela experimentação: “A tradição cultural dos antepassados é valor fundamental e base do fazer pedagógico; preserva-se a tradição da oralidade; valoriza-se o trabalho como meio educativo e como inserção na vida do grupo; o valor fundamental da terra é afirmado constantemente; aprende-se a conhecer e respeitar a natureza" (CIMI-ANE, 2002, p. 24).

Kramer (2005) conclui, em seus estudos, que não é possível educar sem cuidar. Assim, situações que ocorrem diariamente na rotina das crianças que frequentam a educação infantil, como tomar banho, trocar de roupas ou mesmo de fraldas, por exemplo, poderão se transformar num momento educativo e lúdico à medida que o adulto interage com a criança, gerando aprendizado e desenvolvimento.

A questão seguinte foi sobre o relacionamento do professor com os demais membros da comunidade escolar. O PH 1 relata seu relacionamento com os demais professores e a gestão da escola: “é ótimo”, contudo já houve preconceito por parte dos responsáveis pelas crianças. Ele versa:

Todo ano tem alguma coisinha, por exemplo: teve um caso que a mãe de um aluno foi entregar o aluno pra mim e eu fui receber o aluno; ela não me entregou, ela deu a volta e entregou pra recreadora que trabalhava comigo e a recreadora perguntou por que ela não entregou pra mim, né, o filho, por que não entregou para o professor? "Ai, por que eu acho muito estranho um homem ser professor do meu filho". Então, assim, preconceito ainda tem, pelo menos no início do ano acontece, mas depois [pausa]; até nesse dia a irmã dela, que deixou o filho dela também, veio falar que a irmã tava tendo problema na escola e que comigo nunca teve problema, e ela acabou aceitando depois, né, eu faço meu trabalho tal, né, mas tem preconceito, sim. No primeiro ano que eu cheguei aqui teve mãe que não quis deixar o filho comigo por questão de dar banho, então existe preconceito. 
Esse período em que o professor tem que provar sua capacidade para executar as tarefas comuns ao exercício da profissão na educação infantil é o que Ramos (2011) denomina de "período comprobatório". O autor explica seu conceito da seguinte forma: "Durante um tempo, esses docentes precisaram provar que possuíam as habilidades necessárias para educar essas crianças pequenas e cuidar delas com competência, sem machucá-las ou violentá-las sexualmente” (RAMOS, 2011, p. 128).

Novamente o banho das crianças é citado como um ponto delicado na rotina escolar dos professores homens da educação infantil. É interessante notar que a classe desse professor é composta apenas por meninos. $\mathrm{O}$ PH 1 continua sua fala destacando que existe um receio quanto à pedofilia por parte dos responsáveis pelas crianças:

Porque elas [as mães] acham que eu vou ajudar no banho, né. Tem duas auxiliares que trabalham comigo, eles [as crianças] vão brincar lá fora e o banho é com elas, eu fico aqui com os que já tomaram banho. Enquanto tá esperando o banho, eu tô dando outra atividade pra eles, mas as mães acham que eu vou ao banheiro dar banho nas crianças.

O professor detalha que quem normalmente dá banho nas crianças são as professoras de recreação e que, na falta delas, a higiene fica a cargo da diretora, para evitar problemas com as famílias. E, quando questionamos sobre que tipo de problemas eles pretendem evitar, nos responde: “Os pais têm muito [receio], assim [pausa], [de] pedofilia, que hoje é comum. Os pais acham que sendo professor o risco de acontecer é bem maior, nê").

Nesse sentido, Ramos (2011) afirma que o cuidado físico executado por parte dos professores homens representa, para os pais, uma ameaça à integridade física da criança e que a mesma representação não é atribuída às profissionais do sexo feminino:

Eles [os pais] explicitam que, nas ações do cuidar, há restrição apenas para os homens, pois as professoras não representam nenhum tipo de ameaça para as crianças na medida em que trazem consigo a vocação para a maternidade e elas são, por natureza, quem protege e cuida dos filhos com desvelo e são incapazes de cometer maldade contra crianças. (RAMOS, 2011, p. 107).

Devido à resistência apresentada por alguns responsáveis a respeito do toque físico do professor homem na criança, o PH 1 questiona: "Outra coisa que eu me pergunto também é como levam os filhos ao pediatra, aí não tem nenhum preconceito, né, mas com professor tem; vê o professor como 'Ah, é um pedófilo, medo!'. E não tem nada a ver, não são todos os pais, é algum, alguns só, mas eu não entendo por que!"'. 
Cruz (1998, p. 244) sustenta que se encontra, tanto na educação infantil quanto no âmbito familiar, um medo relacionado à concepção da sexualidade masculina como algo incontrolável. Em muitas falas dos entrevistados - às vezes explícitos, outras vezes velados -, encontram-se relatos de receio à pedofilia por parte da comunidade escolar.

O PH 3 declara que não enfrentou preconceito por parte dos responsáveis pelas crianças, mas se deparou com resistência por parte das professoras: “É, de pais não, mas de atendentes, de algumas professoras. Nas reuniões eu percebi, teve professora que chegou pra mim: 'Ah! Você não acha que tá fora da sua área?"”.

O comentário da professora evidencia a representação social de que homens não têm os atributos necessários para o exercício da docência com crianças. Mesmo assim, contudo, o professor destaca a importância da preparação para o exercício da profissão e que a formação é fornecida de maneira igualitária para homens e mulheres. E sublinha que:

É só dar preparo; como é para o homem, ensina ele a trocar uma fralda, ele vai aprender; ensina ele como que vai dar uma mamadeira, como prepara uma mamadeira pra dar para a criança, ele vai aprender [...]. Então tudo é questão de preparo, preparo, que a gente prepara um homem ou uma mulher para exercer uma função. A pessoa faz. Esse negócio de macho e fêmea é tudo bobeira da sociedade. Pura bobeira.

Segundo a LDB de 1996 (BRASIL, 1996), a formação do professor da educação infantil deve ser oferecida em cursos superiores de licenciatura, sendo admitida a formação mínima em nível médio. Ao final de sua preparação, o professor, como indicam Libâneo e Pimenta (2006, p. 44), deve ter as seguintes características:

[...] um profissional do humano: que ajuda o desenvolvimento pessoal, intersubjetivo do aluno; um facilitador do acesso do aluno ao conhecimento (informador/informado); um ser de cultura que domina de forma profunda sua área de especialidade (científica e pedagógico/educacional) e seus aportes para compreender o mundo; um analista crítico da sociedade, que nela intervém com sua atividade profissional; um membro de uma comunidade de profissionais, portanto científica (que produz conhecimentos sobre sua área) e social.

Esse profissional lida para além do aprendizado do aluno, tendo que atender também a toda a comunidade escolar. O PH 2 considera que tem uma boa relação com a comunidade escolar, mas destaca que existe uma vigilância sobre a sua atuação:

Minha relação é boa, mas eu sinto que tem gente que dá uma torcidinha de nariz. Talvez não confie. Eu vejo algumas pessoas passando pela porta dando uma espiadinha, vê o que tá acontecendo. [...] Na hora que as crianças vão dormir, então 
fecha tudo, apaga as luzes e tinha certos receios. A gente escutou algumas coisas neste sentido.

Louro (1999, p. 106) ressalta que “[...] a vigilância é constantemente exercida, podendo ser renovada e transformada, mas ninguém escapa dela". Fazendo referência aos pensamentos de Foucault (2008), Louro (1999, p. 110) destaca que, desde o século XVIII, os construtores e organizadores escolares colocaram-se "num estado de alerta perpétuo" em relação à sexualidade daqueles que circulam na instituição escolar. Sendo assim, para fazer com que homens e mulheres se ajustem aos padrões das comunidades, faz-se necessário ter atenção redobrada sobre aqueles e aquelas que serão os formadores e formadoras das crianças nas escolas.

O PH 4 pondera que, na aldeia indígena, não há estranhamento por parte da comunidade, mas ressalta que causa estranhamento às pessoas da cidade a presença de um homem atuando com crianças:

Eu acho que não, aqui na aldeia, não, mas na cidade, sim, as pessoas sempre perguntam: "Mas você trabalha com criança?". Eu trabalho! "Você trabalha na educação infantil?". Eu trabalho! Pode ser que [a pergunta seja], como você fala cuidar das crianças, se ainda leva no banheiro e aqui a gente não faz isso, né, criança indígena já é diferente.

O professor destaca que, na cultura indígena, as mães são responsáveis pelo cuidado com as crianças em seus primeiros anos de vida, mas, logo que crescem um pouco, os pais começam a "ensinar para a vida”. Este é também o princípio da educação infantil escolar na aldeia:

Eu vou falar porque ela é diferente no meu ponto de vista, educação indígena, porque ela não prepara o aluno só para o mercado de trabalho, porque nem existe isso, né, "Ah, eu vou preparar para trabalhar", "Ah, no Banco do Brasil." Eu não vou preparar para isso, tem que preparar pra vida, pra vida mesmo, para eles construírem, esse é o papel da escola.

Os indígenas encaram a educação das crianças de um modo particular, por isso sua filosofia de educação sobre os processos e as condições de transmissão da cultura, sobre a natureza dos saberes ensinados e sobre as funções sociais da educação se constituíam de modo muito diferente da filosofia educacional adotada pelos não índios.

De acordo com Mandulão, a criança indígena aprende fazendo, experimentando e imitando os adultos. Nessa perspectiva, o autor afirma que "[...] a forma de ensinar nas comunidades indígenas tem como princípios inseparáveis a construção do ser pela observação, pelo fazer, testado dentro de um contexto real” (MANDULÃO, 2003, p. 131). Isso permite dizer que a educação indígena é realizada de modo empírico. Os homens da aldeia participam efetivamente ensinando às crianças a cultura, o que 
justifica o não estranhamento da comunidade em ter um professor do sexo masculino atuando com as crianças.

Para captar as representações sociais dos professores quanto à visão dos pais, as representações dos responsáveis pelas crianças influenciam diretamente no processo escolar. Assim, diante da possibilidade de escolher o sexo do professor de suas crianças, eles optariam pelas mulheres, com raras exceções.

O professor da cidade de Campo Grande e o professor de Corumbá acreditam que os pais escolheriam mulheres para atuar com as crianças e esclarecem as suas respostas: "Porque existe este preconceito do homem na educação infantil, de um homem cuidar, porque a educação infantil é vista pra mulher e não pro homem, então a família normalmente vai optar pela mulher" (PH 1), pois "A nossa sociedade ainda é muito machista, possivelmente escolheriam a mulher" (PH 3).

Em geral, as representações predominantes em famílias de crianças pequenas, matriculadas em instituições de educação infantil, são de que a mulher tem características consideradas femininas, como: paciência, amor materno e "jeito", características apontadas como atributos indispensáveis para o exercício da prática docente com crianças (GONÇALVES; FARIA, 2014).

Essa representação sugere que o professor que atua nessa etapa do ensino faz uso apenas de conhecimentos da prática doméstica, o que leva a supor que o trabalho desses profissionais necessita principalmente de habilidades relacionadas ao cuidado, o que desvaloriza sua formação profissional. É interessante notar que, até o ano de 2013, a educação infantil no município de Campo Grande/MS era responsabilidade da Secretaria de Assistência Social, e o caráter assistencialista essa etapa da educação ainda é muito presente.

Montenegro (2005) ressalta que, em uma sociedade marcada por uma visão assistencialista de atendimento à criança pequena, as mulheres são vistas como naturalmente habilitadas para cuidar e educar, negando com isso a necessidade de formação específica para o desempenho de tais tarefas.

Na questão seguinte, os professores versaram sobre o motivo de poucos homens escolherem a educação infantil para atuarem. O PH 1 destaca como motivo para os homens não optarem pela carreira docente com crianças o preconceito de ser considerado homossexual: "Pelo preconceito, porque há muitos que dizem 'Quem trabalha normalmente na educação infantil é gay', tem muitos que falam que se trabalha na educação infantil é gay, tem muitos que acham que é isso, e o preconceito da família, porque a família vai criticar, não vai aceitar". 
Rabelo, ao estudar professores homens que atuam nos anos iniciais do ensino fundamental, destacou a existência de preconceito da sociedade quanto à opção sexual desses sujeitos. Segundo a autora, muitos professores, mesmo sendo heterossexuais, eram considerados como homossexuais, em razão de a sociedade acreditar que, para atuar com crianças, esses docentes deveriam possuir atributos considerados femininos, como "paciência" e "carinho". Ela ainda afirma que a insinuação da homossexualidade é motivo para "[...] pensamento em abandonar a profissão" (RABELO, 2013, p. 915).

Araújo e Hammes (2012, p. 7) fazem uma consideração relevante quanto à escassez de homens atuando como professores de crianças: “[...] essa ausência ligada ao receio ou medo em relação à pedofilia, ao homossexualismo, a visão de que cuidar de crianças é uma tarefa exclusivamente feminina ou questiona-se se a educação de crianças realmente necessita de homens ou para eles existem outras profissões".

Nesse sentido, o PH 1 evidencia que poucos homens optam pela carreira docente por ser considerada como profissão de mulher: "Eu acredito que é porque a mulher veio para o mercado de trabalho e segundo grau com magistério contribuiu muito pra isso, eu via minha mãe dizer que o magistério era mais pra mulheres e homens vão para contabilidade".

Estudos demonstram que a educação brasileira iniciou com a maioria dos docentes homens e, por diversos motivos, as mulheres foram ocupando esse espaço. Para citar alguns desses estudos, basta lembrar os nomes de Nogueira e Schelbauer (2013), de Caetano e Neves (2013), de Louro (2012) e de Almeida (1998). Para tais autores(as), as mulheres foram direcionadas para esse ofício sob a ideia de a tarefa educativa coadunar-se com as funções maternas. Cabe lembrar que a escolarização de crianças menores de 6 anos é uma conquista posterior à Segunda Guerra Mundial, com poucas exceções, especialmente aquelas instituições de assistencialismo para crianças abandonadas. Antes não havia esse nível de educação infantil no sistema educacional. Então, isso considerado, cabe dizer que a educação infantil, desde o seu princípio em décadas recentes da humanidade, vem sendo executada por mulheres e atualmente existe a representação social de que elas são mais adequadas e preparadas para o exercício da docência com crianças pequenas, especialmente por possuírem o "instinto materno". Essas representações estão intrinsecamente ligadas ao fato de o trabalho com crianças ser considerado "[...] uma atividade de amor, entrega e doação" (LOURO, 2012, p. 450).

Nesse sentido, os professores se expressam de maneira semelhante: "Na educação infantil é mais pelo tabu de que é pra mulheres, era muito o cuidado, a alimentação, os cuidados básicos, mas 
está se quebrando esse tabu, tem poucos, mas tem, acham que na educação infantil é só pra tocar fralda, pra dar banho, e não é só isso" ( $\mathrm{PH} 2$ ). Na verdade, "É muito trabalhoso mesmo, tem que ter paciência de Jó, tem que ter calma”. Como a sociedade não se atenta para esse trabalhoso lado educacional, "Eles (a sociedade) acreditam que é coisa de mulher" (PH 4).

Esse discurso dos professores é reflexo das representações sociais de que "características femininas" são requisitos para o exercício da docência. Almeida (2006, p. 82) aponta que "[...] instruir e educar crianças era considerado não somente aceitável para as mulheres, como era também a profissão ideal em vista destas possuírem moral ilibada, sendo pacientes, bondosas e indulgentes para lidar com os alunos".

Cerisara (2002, p. 63) argumenta: “[...] somente a proximidade ao caráter escolar-formal daria ao trabalho realizado nas instituições de educação infantil pelas professoras uma legitimidade de trabalho competente e profissional, em que não houvesse o risco de cair na substituição materna". É importante ressaltar que a educação dos primeiros anos de vida é o pilar para a construção do sujeito e, portanto, o profissional que atua com essa faixa de ensino, independentemente do sexo, deve ser bem preparado para atender às necessidades de seus alunos.

Diante das discussões dos professores quanto à escassez de homens atuando na educação infantil, perguntamos se eles consideram relevante aumentar esse contingente. Todos concordaram que sim e justificaram as suas respostas. O PH 1 relatou: "Porque é uma forma de acabar com esse preconceito, quanto mais (professores), menos seria o preconceito, quanto mais homens tivesse na educação infantil [ela] se tornaria uma coisa comum, acabaria esse preconceito".

Para o professor, se houvesse mais homens atuando na educação infantil, a presença não causaria estranheza e, consequentemente, não perturbaria. Isso significa tornar o não familiar em familiar, uma das funções das representações sociais. Para Moscovici (2004), o não familiar são as ideias ou as ações que nos perturbam e nos causam tensão. Essa tensão entre o familiar e o não familiar é sempre estabelecida em nossos universos consensuais, em favor do primeiro. Entretanto, o que nos é incomum, não familiar, é assimilado e pode modificar nossas crenças. Esse é o processo de reapresentar o novo.

O PH 3 frisa a importância da mudança da mentalidade da sociedade: "Acredito que, se a sociedade mudar essa mentalidade, possa acontecer isso. Como falei, é preciso trabalhar muito ainda pra mudar esse ranço de machismo, que não somente os homens têm, mas as mulheres também têm". E exemplifica de maneira muito interessante: 
Porque quando eu entrei aqui tinha gente que falava: "Guri não pode brincar com boneca", e eu falei: "Não, tá errado, porque um dia ele vai ser pai, ele vai ter que cuidar do seu filho, da sua filha, e ele vai ter que aprender." Então vamos botar uma fralda na boneca, dá ele essa brincadeira, e você já está ensinando que todo mundo pode cuidar de todo mundo, que um homem pode cuidar de criança, mulher do homem, assim como eu falei, o que tem que acontecer, acima de tudo, é respeito e amor.

As representações sociais quanto ao papel da mulher e do homem na sociedade têm sido revolucionadas, visto que mulheres executam papéis antes atribuídos aos homens, exercendo os mais diversos tipos de trabalho, e também porque, por outro lado, homens atualmente fazem tarefas antes consideradas femininas, como as tarefas domésticas, incluindo cuidar das crianças:

Ainda que articuladas às mudanças sociais, as relações entre homens e mulheres são pautadas por valores e concepções culturais que se vinculam aos papéis sociais historicamente atribuídos ao masculino e ao feminino. É importante destacar que esses papéis se alteraram significativamente nos últimos tempos. (RAMOS, 2011, p. 101).

Assim, a estrutura social tem sido modificada, o que exige uma flexibilidade entre os seus membros, contudo, na área da educação escolar, principalmente na atuação com crianças pequenas, isto ocorre lentamente, pois se percebe uma pequena, porém existente, presença de homens atuando nesta etapa da educação. O PH 2 espontaneamente fala sobre a igualdade de gênero na docência da educação:

Olha, eu acho que o trabalho tanto do homem quanto da mulher na educação infantil é o mesmo. O que muda às vezes é o modo. Às vezes ela faz de uma forma e você vai fazer diferente, o que não quer dizer que um é o melhor. Não posso falar que, por ser homem, vai fazer melhor ou vai fazer pior. Cada um é cada um. Se você entrar em 10 salas diferentes de mulheres, são 10 pessoas diferentes, 10 trabalhos diferentes. Se você entrar em 10 de homens, vão ser 10 trabalhos diferentes. Se você entrar em 5 de homens, 5 de mulheres, vão ser 10 trabalhos diferentes. Não tem diferença. Eu pelo menos não vejo em qualquer etapa da educação diferença de ser homem ou ser mulher. Não tem diferença. A diferença está em cada um. Eu, da forma que eu planejo, do meu comprometimento [...].

O PH 3 complementa: "Tem que ver o que esse homem tem de bom para contribuir".

A pedra fundamental da educação infantil é o desenvolvimento pleno das crianças. Elas também têm um papel como atores sociais e devem ser consideradas como sujeitos produtores de cultura. Suas representações podem ser diferentes da predominante na sociedade. Autores como Ramos (2011), Erden et al. (2011) e Mossburg (2004) relacionam a relevância de se ter professores homens com a necessidade de modelos positivos de masculinidade e com a contribuição para a diversidade e a equidade de gênero na educação. 


\section{Considerações finais}

Refletindo sobre o objetivo do presente estudo, qual seja, de verificar as representações sociais de professores homens que atuam na educação infantil, é possível afirmar que esses sujeitos enfrentam preconceito por atuarem em uma profissão em que a representação social vigente é a de que é a mulher que possui atributos inatos para essa área educacional.

Esses homens precisam provar a sua aptidão para desempenhar as tarefas próprias do oficio, porém, mesmo comprovando, o medo da pedofilia por parte da comunidade escolar cria evidente resistência, em especial quando não é permitido a esses profissionais participar de tarefas que envolvem contato físico com as crianças, como dar banho, trocar roupas ou fraldas, ou quando, em uma turma em que o professor é homem, só meninos a frequentam, enquanto as outras turmas da escola são mistas.

Pelas representações dos professores, existe estranheza por parte dos colegas e dos pais quanto à presença de homens na educação infantil. Essa estranheza pode ser atribuída ao fato de a sociedade estar acostumada à grande presença feminina nas salas de aula da educação infantil, o que lhes é familiar. A aceitação de homens atuando com essa faixa de ensino implicaria tornar o não familiar em familiar. Contudo, é interessante notar que, em nenhum momento, os professores mencionaram preconceito por parte das crianças.

Uma ocorrência que merece destaque é o cuidado físico, muitas vezes necessário nessa etapa da educação, como o banho e a troca de fraldas, que são exemplos citados várias vezes nas entrevistas e nenhum dos professores entrevistados executava essas tarefas, sempre atribuídas a alguma professora mulher, o que denota preconceito por parte da comunidade escolar adulta. Diante dessa situação, podese dizer que essa atividade fica excluída da parte pedagógica da educação, seguindo em sentido contrário ao princípio do binômio educar e cuidar, quando os momentos do cuidado físico deveriam ser apropriados para ensinar.

É notório que a educação infantil adquiriu cunho educativo, reconhecendo a criança como cidadão que possui aspectos fisiológicos, psicológicos, intelectuais, afetivos, sociais e culturais. As crianças necessitam ter convívio com adultos de ambos os sexos, pois são as suas referências de vida, especialmente na escola, local em que elas iniciam a socialização fora da família. Nesse sentido, podese afirmar que homens podem contribuir de forma positiva na educação de crianças.

Diante dos resultados, sugerem-se novas pesquisas com os demais membros da comunidade 
escolar que presenciam a atuação de homens nesse nível educacional, para verificar as suas reais representações sobre professores homens atuando com crianças em instituições de educação infantil. Sugere-se ainda que se estudem os professores homens do ensino fundamental, a fim de verificar suas representações e se também sofrem preconceito de gênero em sua atuação docente.

\section{Notas}

\footnotetext{
${ }^{1}$ Entrevista cedida por PH 1 às autoras [2014]. Campo Grande, MS. 2014. 1 arquivo .mp3 em posse das autoras. As demais citações referem-se à mesma entrevista

${ }^{2}$ Entrevista cedida por PH 3 às autoras [2014]. Corumbá, MS. 2014. 1 arquivo .mp3 em posse das autoras. As demais citações referem-se à mesma entrevista.

${ }^{3}$ Entrevista cedida por PH 4 às autoras [2014]. Tacuru, MS. 2014. 1 arquivo .mp3 em posse das autoras. As demais citações referem-se à mesma entrevista.

${ }^{4}$ Entrevista cedida por PH 2 às autoras [2014]. Itaquiraí, MS. 2014. 1 arquivo .mp3 em posse das autoras. As demais citações referem-se à mesma entrevista
}

\section{REFERÊNCIAS}

ALMEIDA. J. S. Mulheres na educação: missão, vocação e destino? A feminização do magistério ao longo do século XX. In: SAVIANI, D. et al. O legado educacional do século XX no Brasil. São Paulo: Autores Associados, 2006. p. 59-107.

ALMEIDA, P. N. Educação lúdica: técnicas e jogos pedagógicos. 9. ed. São Paulo: Loyola, 1998.

ARAÚJO, P. M.; HAMMES. C. C. A androfobia na educação infantil. Interfaces da Educação, Paranaíba, v. 3, n. 7, p. 5-20, 2012.

ARCE, A. Documentação oficial e o mito da educadora nata na educação infantil. Cadernos de Pesquisa, São Paulo, n. 113, p. 167-184, jul. 2001.

ALVES-MAZZOTTI, A. J. Representações sociais: aspectos teóricos e aplicáveis na educação. Em Aberto, Brasília, n. 61, p. 60-78, 1994.

BRASIL. Constituição da República Federativa do Brasil de 1988. Diário Oficial da União, Brasília, DF, 5 out. 1988 ,

BRASIL. Lei n ${ }^{\circ}$ 9.394, de 20 de dezembro de 1996. Estabelece as diretrizes e bases da educação nacional. Diário Oficial da União, Brasília, DF, 23 dez. 1996.

BRASIL. Ministério da Educação. Referencial Curricular Nacional para Educação Infantil. Brasília, DF: MEC, 1998.

BRASIL. Ministério da Educação. Secretaria de Educação Básica. Diretrizes Curriculares Nacionais para a Educação Infantil. Brasília: MEC/SEB, 2010. 
CAETANO, E.; NEVES, P. E. C. Feminização do magistério: algumas questões. Disponível em: <http://www.histedbr.fae.unicamp.br/acer_histedbr/seminario/seminario8/_files/>. Acesso em: 26 jul. 2014.

CERISARA. A. B. Professoras de educação infantil: entre o feminino e o profissional. 2. ed. São Paulo: Cortez, 2002.

CONSELHO MISSIONÁRIO INDIGENISTA. Textos e pretextos sobre educação indígena. Revista da Articulação Nacional de Educação, ano 2, n. 2, p. 21-39, abr. 2002.

CRAIDY, C. M.; KAERCHER, G. E. P. S. Educação infantil: pra que te quero? Porto Alegre, RS: Artmed, 2001.

CRUZ, E. F. “Quem leva o nenê e a bolsa?”: o masculino na creche. In: ARILHA, M.; RIDENTI, S. G. U.; MEDRADO, B. (Org.). Homens e masculinidades: outras palavras. 34. ed. São Paulo: ECOS, 1998. p. 235-255.

DIDONET, V. Creche: a que veio, para onde vai. In: Educação infantil: a creche, um bom começo. Em Aberto, Brasília, v. 18, n. 73, p. 11-28, 2001.

ERDEN, S.; OZGUN, O.; CIFTCI, M. A. I am a man, but I am a pre-school teacher: self-and socialperception of male pre-school teachers. Procedia Social and Behavorial Sciences, v. 15, p. 3199-3294, 2011.

FOUCAULT, M. Vigiar e punir: nascimento da prisão. Tradução de Raquel Ramalhete. 35. ed. Petrópolis, RJ: Vozes, 2008.

GONÇALVES, J. P. O perfil profissional e representações de bem-estar docente e gênero em homens que tiveram carreiras bem-sucedidas no magistério. 2009. $232 \mathrm{f}$. Tese (Doutorado em Educação) Pontifícia Universidade Católica do Rio Grande do Sul, PUC/RS, Porto Alegre, 2009.

GONÇALVES, J. P.; FARIA, A. H. O que dizem as famílias sobre homens professores trabalhando com crianças de 0 a 3 anos? Análise de suas representações sociais. In: BEZERRA, G. F. (Org.). Pesquisa(s) em educação: múltiplos olhares. Curitiba, PR: CRV, 2014. p. 281-293.

LEVENFUS, R. S. Orientação vocacional ocupacional: a luz da psicanálise. In: LEVENFUS, R. S. Psicodinâmica da escolha profissional. Porto Alegre, RS: Artes Médicas, 1997. p. 227-244.

LIBÂNEO, J. C.; PIMENTA, S. G. Formação dos profissionais da educação: visão crítica e perspectivas de mudança. In: PIMENTA, S. G. (Org.). Pedagogia e pedagogos: caminhos e perspectivas. São Paulo: Cortez, 2006. p. 11-57.

LOURO, G. L. Gênero, sexualidade e educação: uma perspectiva pós-estruturalista. 10. ed. Petrópolis, RJ: Vozes, 1999. 
LOURO, G. L. Mulheres na sala de aula. In: PRIORE. M. D.; PINSK. B. C. (Org.). História das mulheres no Brasil. São Paulo: Contexto, 2012. p. 441-481.

KRAMER, Sônia. A política do pré-escolar no Brasil: a arte do disfarce. 5. ed. São Paulo: Cortez, 1995.

MANDULÃO, F. S. Educação na visão do professor indígena. In: BRASIL. Ministério da Educação. Diversidade na Educação: reflexões e experiências. Brasil: MEC, 2003. p. 129-137.

MINAYO, M. C. S. Pesquisa social: teoria, método e criatividade. Petrópolis, RJ: Vozes, 1998.

MONTENEGRO, T. Educação infantil: a dimensão moral da função de cuidar. Psicologia da Educação, São Paulo, v. 20, p. 77-101, 2005.

MOSCOVICI, S. A social psychological analysis. London: Academic Press, 1973.

MOSCOVICI, S. Representações sociais: investigações em psicologia social. 2. ed. Petrópolis, RJ: Vozes, 2004.

MOSSBURG, M. W. Male early childhood teachers: shaping their professional identity. Pro-quest dissertations and theses, 2004. 630 f. Tese (Doutorado em Educação) - Arizona State University (EUA), Arizona, 2004.

NOGUEIRA, K. J.; SHELBALUER, R. A. Feminização do magistério no Brasil: o que relatam os pareceres do Primeiro Congresso da Instrução do Rio de Janeiro. Disponível em:

<http://www.histedbr.fae.unicamp.br/acer_histedbr/jornada/jornada7/_GT1\%20PDF/FEMINIZA\%C7 \%C3O\%20DO\%20MAGIST\%C9RIO\%20NO\%20BRASIL.pdf>. Acesso em: 22 jul. 2015.

RABELO, A. O. Professores discriminados: um estudo sobre os docentes do sexo masculino nas séries do ensino fundamental. São Paulo. Educação e Pesquisa, São Paulo, v. 39, n. 4, p. 907-925, out./dez. 2003.

RAMOS, J. Um estudo sobre os professores homens da educação infantil e as relações de gênero na Rede Municipal de Belo Horizonte - MG. 2011. 139 f. Tese (Doutorado em Educação) - Pontifícia Universidade Católica de Minas Gerais, Minas Gerais, 2011. Disponível em: $<$ http://www.biblioteca.pucminas.br/teses/Educacao_RamosJ_1.pdf>. Acesso em: 15 abr. 2015.

RIZZO, G. Creche: organização, currículo, montagem e funcionamento. 3. ed. Rio de Janeiro: Bertrand Brasil, 2003.

SÁ, C. P. Representações sociais: o conceito e o estado atual da teoria. In: SPINK, M. J. (Org.). O conhecimento no cotidiano. São Paulo: Brasiliense, 1995. p. 19-45.

SANTOS, M. O. V. A identidade da profissional de educação infantil. In: GUIMARÃES, C. M. (Org.). Perspectivas para a educação infantil. São Paulo: Junqueira e Martin, 2005. p. 87-101. 
SAYÃO, D. Relações de gênero e trabalho docente na educação infantil: um estudo de professores em creche. 2005. 274 f. Tese (Doutorado em Educação) - Programa de Pós-Graduação em Educação, Universidade Federal de Santa Catarina, Florianópolis, 2005.

SCOTT, J. Gênero: uma categoria útil de análise histórica. Educação e Realidade, Porto Alegre, v. 2, n. 20, p. 71-99, jul./dez. 1998.

SOARES, D. H. A escolha profissional: do jovem ao adulto. São Paulo: Summus, 2002.

SPINK, M. J. P. O estudo empírico das representações sociais. In: SPINK, M. J. P. (Org.). $O$ conhecimento no cotidiano: as representações sociais na perspectiva da psicologia social. São Paulo: Brasiliense, 1995. p. 85-108.

WALLON. H. A evolução psicológica da criança. 2. ed. Lisboa: Edições 70, 1995. 


\section{Teacher education child looks men: achievements and prejudice}

\begin{abstract}
The objective of this research is to ascertain what the social representations of male teachers who work with children aged 0-5 years enrolled in public institutions of early childhood education in the state of Mato Grosso do Sul The methodology was used semi-structured interviews that. were audiorecorded, transcribed and analyzed from the perspective of social representations, with teachers from four municipalities of that State. The results indicate that male teachers are limited in their activity as it is not permitted to perform tasks proper to the profession as bathing and changing diapers, for fear of pedophilia is evident. Discussions suggest that few men opt for the teaching profession, due to be considered a female profession. In conclusion, it can be said that early childhood education should give children contact with adults who are their references, of both sexes, especially at school, place where they begin socializing outside the family. In this sense, it can be said that men can contribute positively to the process of education of children.
\end{abstract}

Keywords: Social representations. Childhood education. Male teachers.

\section{Josiane Peres Gonçalves}

E-mail: josianeperes@zipmail.com.br

Adriana Horta de Faria

E-mail: adrianahortadefariafaria@yahoo.com.br

Maria das Graças Fernandes de Amorim dos

Reis

E-mail: gmgrg@ig.com.br
Educación del profesorado el niño mira men: $\operatorname{logros}$ y prejuicio

\section{Resumen}

El objetivo de esta investigación es determinar cuáles son las representaciones sociales de los profesores varones que trabajan con niños de 0-5 años matriculados en instituciones públicas de educación infantil en el estado de Mato Grosso do entrevistas semiestructuradas Sul se utilizó la metodología. fueron audio grabadas, transcritas y analizadas desde la perspectiva de las representaciones sociales, con los maestros de cuatro municipios de dicho Estado. Los resultados indican que los profesores varones están limitados en su actividad, ya que no está permitido para realizar tareas propias de la profesión como los pañales de baño y cambiantes, por miedo a la pedofilia es evidente. Los debates sugieren que algunos hombres optan por la profesión docente, por ser considerada una profesión femenina. En conclusión, se puede decir que la educación de la primera infancia debe dar a los niños en contacto con adultos que son sus referencias, de ambos sexos, especialmente en la escuela, el lugar donde comienzan socializar fuera de la familia. En este sentido, se puede decir que los hombres pueden contribuir positivamente al proceso de la educación de los niños.

Palabras claves: Representaciones Sociales. Educación de la Primera Infancia. Maestros Varones.

Enviado em: 28/8/2015

Aprovado em: 15/9/2016 